\title{
Challenges of Clinical Chemistry Analyzers Utilization in Public Hospital Laboratories of Selected Zones of Oromia Region, Ethiopia: A Mixed Methods Study
}

\author{
Rebuma Belete $^{1 *}$, Waqtola Cheneke ${ }^{2}$, Aklilu Getachew ${ }^{2}$ and Ahmedmenewer Abdu ${ }^{1}$ \\ ${ }^{1}$ Department of Medical Laboratory Sciences, College of Health and Medical Sciences, Haramaya University, Harar, Ethiopia \\ ${ }^{2}$ School of Medical Laboratory Sciences, Faculty of Health Sciences, Institute of Health, Jimma University, Jimma, Ethiopia
}

*Corresponding author: Rebuma Belete, Department of Medical Laboratory Sciences, College of Health and Medical Sciences, Haramaya University, Harar, Ethiopia

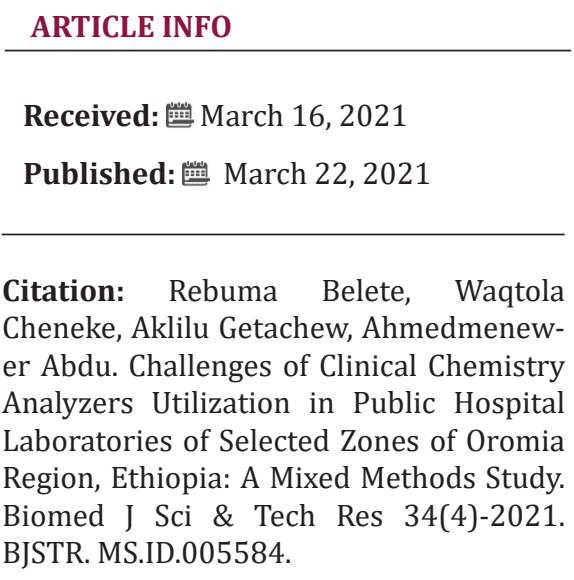

Keywords: Clinical Biochemistry; Automation; Chemistry Analyzers

\section{ABSTRACT}

Background: The modern practice of clinical chemistry relies ever more heavily on automation technologies. Their utilization in clinical laboratories in developing countries is greatly affected by many factors. Thus, this study was aimed to identify challenges affecting clinical chemistry analyzers utilization in public hospitals of selected zones of Oromia region, Ethiopia.

Methods: A cross-sectional study using quantitative and qualitative methods was conducted in 15 public hospitals from January 28 to March 15, 2019. Purposively selected 68 informants and 93 laboratory personnel working in clinical chemistry section were included in the study. Data were collected by self-administered questionnaires, in-depth interviews and observational checklist. The quantitative data were analyzed by descriptive statistics using SPSS 25.0 whereas qualitative data was analyzed by a thematic analysis.

Results: We identified major challenges affecting the utilization of clinical chemistry analyzers in the surveyed hospitals. These are: wide variety of analyzers, nonfunctionality of analyzers, lack of user training, reagents shortage, inappropriate procurement processes of analyzers, underuse of clinical chemistry tests and poor infrastructure.

Conclusion: Due to many challenges, clinical chemistry analyzers in the studied hospitals were not utilized appropriately. To overcome this problem, we recommend that standardization of clinical chemistry analyzers should be implemented at national level.

\section{Introduction}

Clinical laboratory services have a great influence on clinical decisions and $60-70 \%$ of the most important decisions on admission, discharge, and medication are based on laboratory results [1]. Due to this overwhelming dependence of clinical decisions on laboratory reporting, clinical laboratories have to improve their services. The key to improvement of laboratory services is the implementation of correct automation technologies [1,2]. The utilization of automation technology in clinical laboratories of developing countries is greatly affected by many factors such as their malfunction and absence of their maintenance, shortage of laboratory consumables, inadequate logistical support, absence of governmental standards, poor laboratory infrastructure and shortage of well-trained laboratory staff $[3,4]$.

In low-income countries, as much as half of the equipment in medical institutions are inoperable and not in use whereas some estimation is ranging up to $96 \%$ [5]. Poor medical equipment handling and utilization, frequent power surges, the ages of the equipment, lack of operator training, lack of preventive maintenance, lack of spare parts, lack of maintenance capacity, and minimal knowledge regarding sophisticated equipment 
are factors that contribute to equipment breakdowns [6]. The modern practice of clinical chemistry relies ever more heavily on automation $[7,8]$. Thus, identifying the different challenges relating to clinical chemistry automation utilization faced by laboratories is important to work on and resolve those obstacles. Therefore, this study was aimed to identify challenges of clinical chemistry analyzers utilization in public hospital laboratories of selected zones of Oromia region, Ethiopia.

\section{Materials and Methods}

\section{Ethics Statement}

Ethical clearance was obtained from the Institutional Review Board of Institute of Health, Jimma University (IRB approval number: JHRPGD/590/2018). Permission was obtained for observation of hospital laboratories and their clinical chemistry analyzers. Participants were informed about the purpose, benefits, risks, autonomy to participate and the right to withdraw or refuse to participate in the study at any time. Throughout the study period, confidentiality of the data was strictly followed. Informed written and signed consent was obtained from all participants.

\section{Study Design, Period and Setting}

A cross-sectional study was conducted using mixed quantitative and qualitative methods from January 28 to March 15, 2019. The study was conducted in 15 public (owned by government) hospitals found in 4 selected zones (Jimma, Ilubabor, Southwest Shoa and Buno-Bedele) of Oromia region, Ethiopia. The included hospitals were Jimma, Shanan Gibe, Limu Genet, Setema, Omo Nada, Seka Chokorsa, Agaro, Dhidhesa, Bedele, Matu Karl, Darimu, Tulubolo, Ameya, Bantu and Leman.

\section{Data Collection}

Checklist (S1 Checklist) was used to collect detailed information concerning the facilities and clinical chemistry analyzers. Questionnaire (S1 Questionnaire) was used to collect data such as sociodemography, educational level, working experience, training and skills status from all laboratory professionals $(n=93)$ who were working in clinical chemistry section and volunteer to participate. First, the respondents were communicated to get their consent. Once their consent was known, the prepared questionnaires were distributed to each participant. Then, filled questionnaires were collected by checking the completeness of the data.

In-depth interviews were conducted with 68 purposively selected professionals coming from various origins using interview guide (S2 Guide). Three clinical directors, 2 finance heads and 2 laboratory heads refused to participate in the study. Before engaging in the interview, a suitable time and an outlying office in hospitals were arranged for interviews. Then, face-to-face interviews were conducted in Afaan Oromoo by the first author. Responses were audio-recorded, lasting between 22-30 minutes, and field notes were also taken.

\section{Data Analysis}

The quantitative data were cleaned by EPI-Data 3.1, then exported to SPSS version 25 (IBM, USA) and analyzed using descriptive statistics. Qualitative data was analyzed using a thematic analysis. Qualitative analysis software NViVOv.10.0 (QRS International Pty Ltd, Melbourne, Australia) was used to aid this process. The first author transcribed the interviews and then translated into English. The second and third authors reviewed the transcripts and coded units into categories. Each category was then reviewed by the last author and grouped into major themes and finally written by narrating texts and quotation of verbatim.

\section{Data Quality Assurance}

All data collection tools, which were developed for this study, reviewed by experts and validated before data collection by pilot study. During data collection, filled questionnaires and checklists were checked for completeness and validity. The transcribed and translated data obtained from in-depth interviews were read and checked multiple times against the recorded audio for accuracy of verbatim and transcripts.

\section{Results}

\section{Description of Hospitals}

Out of 15 hospitals included in the study, 8 (53.3\%) were primary hospitals, 5 (33.3\%) were general hospitals and 2 (13.3\%) were specialized hospitals. Regarding duration of service, 8 (53.3\%) hospitals had less than 5 years of service whereas 7 (46.7\%) had greater than or equal to 5 years of service.

\section{Background Characteristics of Study Participants}

Among 93 survey participants, 76 (81.7\%) of them were males. Most of the respondents were within 25-29 age group (49.5\%), BSc holders $(75.2 \%)$ and had greater than 5 years of working experience $(44.1 \%)$. Out of 68 in-depth interview participants, 12 were clinical directors, 13 were laboratory heads, 15 were laboratory quality officers, 13 were finance heads and 15 were pharmaceutical storekeepers (Table 1). 
Table 1: Background characteristics of study participants.

\begin{tabular}{|c|c|c|c|c|c|c|c|}
\hline \multirow{3}{*}{ Variables } & \multirow{3}{*}{ Categories } & \multirow[b]{2}{*}{$\begin{array}{c}\text { Survey } \\
\text { participants } \\
(n=93)\end{array}$} & \multicolumn{5}{|c|}{ In-depth interview participants $(n=68)$} \\
\hline & & & $\begin{array}{c}\text { Laboratory } \\
\text { heads }(n=13)\end{array}$ & $\begin{array}{c}\text { Laboratory } \\
\text { quality officers } \\
\quad(n=15)\end{array}$ & $\begin{array}{c}\text { Clinical } \\
\text { directors } \\
(\mathrm{n}=12)\end{array}$ & $\begin{array}{c}\text { Pharmacy } \\
\text { storekeepers } \\
(\mathrm{n}=15)\end{array}$ & $\begin{array}{c}\text { Finance heads } \\
\quad(n=13)\end{array}$ \\
\hline & & $\mathrm{N}(\%)$ & $\mathrm{N}(\%)$ & $\mathrm{N}(\%)$ & $\mathrm{N}(\%)$ & N (\%) & $\mathrm{N}(\%)$ \\
\hline \multirow{2}{*}{ Sex } & Male & $76(81.7)$ & $12(92.3)$ & $13(86.7)$ & $12(100.0)$ & $7(46.7)$ & $10(77.9)$ \\
\hline & Female & $17(18.3)$ & $1(7.7)$ & $2(13.3)$ & $0(0.0)$ & $8(53.3)$ & $3(23.1)$ \\
\hline \multirow{6}{*}{$\begin{array}{l}\text { Age group (in } \\
\text { years) }\end{array}$} & $20-24$ & $11(11.8)$ & $0(0.0)$ & $1(6.7)$ & $0(0.0)$ & $3(20.0)$ & $0(0.0)$ \\
\hline & $25-29$ & $46(49.5)$ & $4(30.8)$ & $3(20.0)$ & $0(0.0)$ & $4(26.7)$ & $0(0.0)$ \\
\hline & $30-34$ & $24(25.8)$ & $8(61.5)$ & $8(53.3)$ & $10(83.3)$ & $5(33.3)$ & $7(53.8)$ \\
\hline & $35-39$ & $12(12.9)$ & $1(7.7)$ & $2(13.3)$ & $2(16.7)$ & $3(20.0)$ & $4(30.8)$ \\
\hline & $40-44$ & $0(0.0)$ & $0(0.0)$ & $0(0.0)$ & $0(0.0)$ & $0(0.0)$ & $2(15.4)$ \\
\hline & $45-49$ & $0(0.0)$ & $0(0.0)$ & $1(6.7)$ & $0(0.0)$ & $0(0.0)$ & $0(0.0)$ \\
\hline \multirow{4}{*}{$\begin{array}{l}\text { Educational } \\
\text { level }\end{array}$} & MD & $0(0.0)$ & $0(0.0)$ & $0(0.0)$ & $12(100.0)$ & $0(0.0)$ & $0(0.0)$ \\
\hline & MSc & $2(2.2)$ & $0(0.0)$ & $0(0.0)$ & $0(0.0)$ & $0(0.0)$ & $0(0.0)$ \\
\hline & $\mathrm{BSc} / \mathrm{BA}$ & $70(75.2)$ & $11(84.6)$ & 13 (86.7) & $0(0.0)$ & $1(6.7)$ & $10(77.9)$ \\
\hline & Diploma & $21(22.6)$ & $2(15.4)$ & 2 (13.3) & $0(0.0)$ & $14(93.3)$ & 3 (23.1) \\
\hline \multirow{3}{*}{$\begin{array}{c}\text { *Work } \\
\text { experience (in } \\
\text { years) }\end{array}$} & $<2$ & $32(34.4)$ & $1(7.7)$ & 2 (13.3) & $4(33.3)$ & $3(20.0)$ & $1(7.7)$ \\
\hline & 02-May & $20(21.5)$ & 7 (53.8) & $9(60.0)$ & 5 (41.7) & 7 (46.7) & $4(30.8)$ \\
\hline & $>5$ & $41(44.1)$ & $5(38.5)$ & 4 (26.7) & $3(25.0)$ & 5 (33.3) & 8 (61.5) \\
\hline
\end{tabular}

MD, Medical Doctor

*for indepth interview participants indicates duration of current position

\section{Description of Clinical Chemistry Analyzers}

Out of 31 clinical chemistry analyzers assessed, 25 (80.8\%),
$25(80.8 \%)$ and $23(74.2 \%)$ were general chemistry analyzers, fully automated analyzers and open reagent system analyzers respectively (Table 2).

Table 2: Description of clinical chemistry analyzers by the level of hospitals $(n=31)$.

\begin{tabular}{|c|c|c|c|c|c|}
\hline \multirow{2}{*}{ Variables } & \multirow{2}{*}{ Categories } & \multicolumn{3}{|c|}{ Number of analyzers by level of hospital } & \multirow{2}{*}{ Total N (\%) } \\
\hline & & Primary & General & Specialized & \\
\hline \multirow{4}{*}{ Analyzer type } & General chemistry & 9 & 11 & 5 & $25(80.8)$ \\
\hline & Immunoassay & 0 & 0 & 2 & $2(6.4)$ \\
\hline & $\begin{array}{c}\text { Integrated chemistry / } \\
\text { immunoassay }\end{array}$ & 0 & 0 & 2 & $2(6.4)$ \\
\hline & Electrolyte analyzer & 0 & 0 & 2 & $2(6.4)$ \\
\hline \multirow{2}{*}{ Automation grade } & Semi-automated & 3 & 3 & 0 & $6(19.2)$ \\
\hline & Fully automated & 6 & 8 & 11 & $25(80.8)$ \\
\hline \multirow{2}{*}{ Reagent form } & Open system & 9 & 11 & 3 & $23(74.2)$ \\
\hline & Closed system & 0 & 0 & 8 & $8(25.8)$ \\
\hline \multirow{2}{*}{$\begin{array}{l}\text { Condition when } \\
\text { received/purchased }\end{array}$} & New & 9 & 11 & 11 & $31(100.0)$ \\
\hline & Reconditioned & 0 & 0 & 0 & $0(0.0)$ \\
\hline
\end{tabular}

\section{Challenges of Clinical Chemistry Analyzers Utilization}

Wide Variety of Analyzers: As shown in Table 3, there were 14different makes and models of clinical chemistry analyzers in the assessed hospital laboratories. The most widely used analyzer was Dirui CS-T240 (22.6\%) followed by Biosystem A25 (12.9\%). 
Table 3: Types and number of clinical chemistry analyzers $(n=31)$.

\begin{tabular}{|c|c|}
\hline Clinical chemistry analyzer & N (\%) \\
\hline Dirui CS-T240 (Dirui Industrial Co., Ltd, China) & $4(22.6)$ \\
\hline Biosystem A25 (BioSystems SA, Spain) & $3(9.7)$ \\
\hline Biosystem BTS 350 (BioSystems SA, Spain) & $3(9.7)$ \\
\hline Mindray BS 200E (Mindray Bio-Medical Electronics Co., Ltd, China) & $2(6.5)$ \\
\hline HumX Pentra 400 (Horiba ABX, France) & $2(6.5)$ \\
\hline COBAS Integra 400 Plus (Roche Diagnostics) & $2(6.5)$ \\
\hline VIDAS ® (BioMérieux SA, France) & $2(6.5)$ \\
\hline Humalyte plus 3 (Human GmbH, Germany) & $1(3.2)$ \\
\hline Opt Lion (OPTI Medical Systems, Inc., Georgia, USA) & $1(3.2)$ \\
\hline SBA 733 plus (Sunostik Medical Technology Co.,Ltd,China) & $1(3.2)$ \\
\hline Photometer 5010 V5+ (Robert Riele GmbH \& Co KG, Germany) & $1(3.2)$ \\
\hline Vegasys (AMS Diagnostics) & $1(3.2)$ \\
\hline 3000 Evolution (BSI) & $1(3.2)$ \\
\hline
\end{tabular}

Concerning the problems encountered the laboratory due to diversity of clinical chemistry analyzers, laboratory head of one hospital said:

"Clinical chemistry analyzers you find in this hospital and other hospitals are different. Even though someone is an expert on one model of clinical chemistry analyzer, he/she may not on others." (Laboratory head 14)

Laboratory quality officer of other hospital explained it as follows:

"Different brands and models of clinical chemistry analyzers are found in different laboratories. This makes difficulty to get support such as reagents during stock out and other consumables from neighbor hospitals." (Laboratory quality officer 7)

Non-Functionality of Analyzers: About 14 (45\%) clinical chemistry analyzers were non-functional whereas 7 (23\%) of them were functional but not in use; totally 21 (68\%) analyzers were outof-service during the study period. The causes of non-functionality were installation problem $(n=4)$, hardware malfunction $(n=9)$, calibration and/or quality control failure $(n=1)$ whereas the causes for functional but not in use of analyzers were reagent shortage $(n=5)$ and lack of user training $(n=2)$. In one hospital, 3 analyzers had been kept without installation for 6 years because of vendor engineer unavailability. Furthermore, there were no service agreements in place between vendors and hospitals for 29(93.3\%) analyzers. The reasons why curative maintenances were not done for non-functional analyzers were due to delayed responses to repair requests $(n=7)$ and unavailability of spare parts $(n=6)$ whereas the curative maintenance of one analyzer was on progress during the study period. One of laboratory heads indicated the problem of analyzer maintenance by saying:
"The vendor engineers delay our request for maintenance of the analyzer. There was a time we wait for them for up to 4 months. The reason they give for delay is that there are few service engineers for many analyzers throughout the country. Many times, we got technical support for minor troubleshoots from the vendor engineers by contacting them through telephone." (Laboratory head 13)

Curative maintenances of clinical chemistry analyzers were also challenging in the assessed hospitals due to its expensiveness when compared to the financial capacity of the hospitals.

"Curative maintenance fee asked by vendor representative engineers is not affordable. They are also not interested to show the curative maintenance procedures to onsite biomedical engineers and to laboratory personnel." (Laboratory quality officer 10)

Reagents Shortage: During the study period, 7 (46.7\%), 8 (53.3\%), 9 (60.0\%) and 5 (33.3\%) hospitals had stock-out for clinical chemistry quality control (normal), clinical chemistry quality control (pathological), calibrator and all assay reagents respectively. Laboratory heads of hospitals indicated the problem of reagents shortage as follows:

"Stock-out of clinical chemistry reagents happens more frequently than other reagents in this hospital. Since we receive nearly expired reagents from Ethiopian Pharmaceuticals Supply Agency, stock-out occurs within a short period of time after procurement. The analyzer had given service for not more than four months in two years due to frequent reagent shortage occurrences." (Laboratory head 9)

"Currently we are giving the service of only four clinical chemistry tests: creatinine, urea, aspartate aminotransferase and alanine aminotransferase due to reagent shortage. Both the vendor of the analyzer and Ethiopian Pharmaceuticals Supply Agency supply only the most frequently ordered reagents." (Laboratory head 7) 
"Even though clinical chemistry analyzer in this laboratory is an open system, there are difficulties to adapt to reagents from other manufacturers. It failed calibration for reagents from many other manufacturers." (Laboratory head 10)

There were 3 open system analyzers which did not adapt to other manufacturers' reagents. As clearly indicated by respondents, this was done intentionally by manufacturers' and/or their vendors for the benefit they get from the sale of reagents.
Lack of End-Users Training: Only 14 (15.1\%) of the laboratory personnel had received user training. The trained individuals were also concentrated in a few hospitals. In addition, the respondents showed that users' training duration were from 1-2 days and mostly procedural orientation only. Furthermore, 49 $(52.7 \%)$ and $74(79.6 \%)$ of study subjects responded they could not perform quality control and calibration of clinical chemistry tests respectively (Table 4).

Table 4: Training and skills related to clinical chemistry automation utilization of study participants ( $\mathrm{n}=93$ ).

\begin{tabular}{|c|c|c|c|}
\hline Variables & \multicolumn{2}{|l|}{ Categories } & $\mathbf{N}(\%)$ \\
\hline \multirow{2}{*}{$\begin{array}{l}\text { Taking training on clinical chemistry } \\
\text { analyzer(s) in the hospital }\end{array}$} & \multicolumn{2}{|l|}{ Yes } & 14 (15.1) \\
\hline & \multicolumn{2}{|l|}{ No } & 79 (84.9) \\
\hline \multirow{3}{*}{$\begin{array}{l}\text { Knowledge on principle of clinical chemistry } \\
\text { tests }\end{array}$} & \multicolumn{2}{|l|}{ Yes } & $29(31.2)$ \\
\hline & \multicolumn{2}{|l|}{ Partly } & $37(39.8)$ \\
\hline & \multicolumn{2}{|l|}{ No } & $27(29.0)$ \\
\hline \multirow{10}{*}{$\begin{array}{c}\text { Activities the laboratory personnel can } \\
\text { perform }\end{array}$} & \multirow{2}{*}{ Running test } & Yes & $88(94.6)$ \\
\hline & & No & $5(5.4)$ \\
\hline & \multirow{2}{*}{ Calibration } & Yes & $19(20.4)$ \\
\hline & & No & $74(79.6)$ \\
\hline & \multirow{2}{*}{ Quality control running and monitoring } & Yes & $44(47.3)$ \\
\hline & & No & $49(52.7)$ \\
\hline & \multirow{2}{*}{ Preventive maintenance } & Yes & $25(26.9)$ \\
\hline & & No & $68(73.1)$ \\
\hline & \multirow{2}{*}{$\begin{array}{c}\text { Troubleshooting minor problems of } \\
\text { analyzer(s) }\end{array}$} & Yes & $18(19.4)$ \\
\hline & & No & 75 (80.6) \\
\hline
\end{tabular}

Laboratory quality officers also explained the severity of the problem by saying:

"The training given by the vendor representative engineer was not satisfactory. The engineer showed us only operation procedures of a limited number of tests for a day. Even though the analyzer can analyze the electrolytes, we could not perform using this analyzer because of skill gap." (Laboratory quality officer 3)

"During the installation of the analyzer the vendor engineer had given training for two laboratory personnel. Both left this hospital; no re-training was given." (Laboratory quality officer 4 )

Inappropriate Selection and Procurement Process of Analyzers: Out of 31 clinical chemistry analyzers, 19 (61\%) were supplied by Oromia regional health bureau or Ethiopian ministry of health, 9 (29\%) were purchased by the hospitals and 2 (7\%) donated from non-governmental organizations. The source of 1 (3\%) analyzer was unknown. Detailed technical and performance review was not done for all analyzers purchased by the hospitals. There was also no formal pre-purchase consultation system in all laboratories.

Laboratory heads indicated the challenges as follows:
".... There are also no criteria for procurement of analyzers at our hospital level. We ask laboratory personnel we know from other hospitals for best analyzer. There is no formal pre-purchase consultation system with experts. In addition, we have no information whether consultants in this area available or not." (Laboratory head 7)

"Four years ago, I had purchased a semi-automated clinical chemistry analyzer. The salesperson tried to install it but now it is non-functional because of incomplete installation." (Laboratory head 14)

Laboratory quality officer of other hospital stated the problem by saying:

"The clinical chemistry analyzer we purchased is an open system. But it does not work with reagents from other manufacturers. The analyzer also not stable; frequent breakdown occurs. This is the result of inappropriate selection and procurement, which is not based on predefined criteria. Detail review and comparison with other brand and model was not done." (Laboratory quality officer 10)

Underuse of Clinical Chemistry Tests: Out of surveyed hospital laboratories, 7 (46.6\%) of them were not give clinical 
chemistry services whereas 3 (20.0\%) of them had performed less than 5 clinical chemistry tests per day in average. Furthermore, about 5 (33.3\%) of hospitals had performed only 1 to 5 clinical chemistry parameters during the study period. Moreover, the laboratory personnel of some hospitals especially of primary hospitals explained that health care providers did not request clinical chemistry tests which in turn cause under usage of the tests.

"Clinical chemistry tests requested rarely. We perform only 1 or 2 clinical chemistry test(s) per week by the analyzer. This causes expiration of analyzer consumables without service." (Laboratory head 2)

Poor Laboratory Infrastructure: In the studied hospital laboratories, there were also challenges of infrastructures that had affected proper utilization of clinical chemistry automation. Power fluctuation, distilled water shortage and uncontrolled room temperature were among the identified. All the assessed hospital laboratories had electric power supply and functional generator for power back up. But there were complains of power fluctuation in most hospitals as explained by informants. There was no control system of temperature in surveyed hospital laboratories clinical chemistry section except one hospital.

"Clinical chemistry and hematology section has no temperature controlling system. The analyzer always shows error relating with high temperature. This is highly affecting our analysis." (Laboratory quality officer 2)

All laboratories used distilled water for clinical chemistry analyzers, but there was shortage. The hospitals vary by their source of distilled water. Only 2 (13.0\%) of them had functional distillers to prepare distilled water for laboratory use. About 3 (20.0\%) hospital laboratories were using car battery water by purchasing from shops while $4(27.0 \%)$ were using bottled water which prepared for human consumption. The other 6 (40.0\%) hospitals were using distilled water procured from Ethiopian Pharmaceuticals Supply Agency. One interviwee explained the shortage of distilled water for clinical chemistry use by saying:

"The hospital has 2 fully automated clinical chemistry analyzers. One analyzer became out of service because it consumes high volume of distilled water i.e., up to 6 liters per hour. It is unaffordable to purchase distilled water for this analyzer since the water distiller we have produces not more than one liter per day." (Laboratory head 10)

\section{Discussion}

Clinical chemistry analyzer brands and model's diversity was the major challenge that affected their utilization in the studied hospitals. There were 14 different types of clinical chemistry analyzers. As clearly indicated in in-depth interviews, this variety was occurred due to lack of proper analyzers standardization at national level. Even though there are standard lists of laboratory equipment at each level of hospitals in Ethiopia [9-11], they are not satisfactory to limit brand and model diversity of clinical chemistry analyzers. This creates difficulties in procuring reagents because each brand of analyzer usually has unique or brand-specific reagents and other commodities (as they are often closed systems) that must be used with that analyzer. In addition, different kinds of analyzers need different kinds of spare parts. This also results in difficulty in availability of spare parts. Furthermore, providing training for end-users and biomedical engineers is difficult when there are large varieties of clinical chemistry analyzers.

A survey conducted in the Jimma Zone, Ethiopia showed that in 20 clinical laboratories there were 10 different types of clinical chemistry autoanalysis equipment [12]. Another study conducted in 15 African and Caribbean countries supports this study where there were about 37 different manufacturers and more than 130 platforms of clinical chemistry [13].

Non-functionality of clinical chemistry analyzers was also another major challenge for their utilization. During the study period, 21 (68\%) of clinical chemistry analyzers were out of service due to an installation problem, hardware malfunction, calibration and quality control failure, reagent shortage and lack of user training. A study conducted in Jimma zone revealed 33.3\% of clinical chemistry analyzers were out of service [14] and other study showed that about $39 \%$ of medical equipment found in Ethiopian public hospitals and other facilities was out of service at any one time [5]. Another study reported that over $50 \%$ of the medical equipment in developing countries is not functioning, not used correctly or not maintained, with some being entirely unnecessary or inappropriate to fulfil its intended purpose [15]. World Health Organization estimated $70 \%$ of laboratory and medical equipment in resource poor settings is out of service due to mismanagement of the technology acquisition process, lack of user-training and lack of effective technical support [16].

This study showed that the majority of the laboratories were unable to give clinical chemistry testing service due to reagents shortage. Stock-outs of quality control (normal), quality control (pathological), calibrator and assay reagents were occurred in 7 (46.7\%), 8 (53.3\%), $9(60.0 \%)$ and 5 (33.3\%) hospitals respectively. Challenges related to laboratory supplies were also reported in Jimma zone [14], Addis Ababa [17] and Sub-saharan Africa [3]. According to Ethiopian hospital reform implementation guidelines, laboratory equipment should only be used by appropriately trained staff [6]. World Health Organization also recommends the vendor should be obliged to train laboratory personnel in the calibration and operation [18].

However, in this study, 79 (84.9\%) of the clinical chemistry 
analyzer operators had not received user training. Due to lack of training, only 19 (20.4\%), 44 (47.3\%) and 25 (26.9\%) of them responded they could perform calibration, quality control running and monitoring and preventive maintenance without supervision respectively. Similar challenge also reported in studies done in Jimma zone [14] and Addis Ababa [19]. The selection criteria used were only automation grade (semi-automated/fully automated) and the cost of the analyzer. According to World Health Organization procurement guideline, selection criteria should include detail review of equipment quality specifications and product specifications [18].

\section{Limitations}

The use of non-probability sampling was probably the main impediment to the generalizability of results. In addition, we didn't conduct in-depth interviews with biomedical engineers from respective hospitals, zonal health departments, Oromia regional health bureau and Ethiopian Public Health Institute which might reveal the root cause of these challenges.

\section{Conclusion}

In summary, we identified major challenges that affected the utilization of clinical chemistry analyzers. Identified challenges were wide variety of clinical chemistry analyzers, non-functionality of analyzers, lack of user training on analyzers, clinical chemistry reagents shortage, inappropriate procurement process of the analyzers, underuse of clinical chemistry tests and poor infrastructures. Due to these barriers, clinical chemistry analyzers in the studied hospitals were not utilized appropriately. To overcome these problems, standardization of clinical chemistry analyzers at national level is needed by limiting to a small range of platforms and updates it within a certain period of time. The institutions should also focus on their infrastructure's improvement to appropriately utilize sophisticated clinical chemistry analyzers.

\section{Acknowledgment}

We would like to thank Institute of Health of Jimma University for funding this study. We also thank the study subjects and facilities as well as those who directly or indirectly had contribution to this study.

\section{References}

1. Plebani M (2006) Errors in clinical laboratories or errors in laboratory medicine? Clin Chem Lab Med 44(6): 750-759.
2. Streitberg GS, Bwititi PT, Angel L, Sikaris KA (2015) Automation and expert systems in a core clinical chemistry laboratory. J Assoc Lab Autom 14(2): 94-105.

3. Petti CA, Polage CR, Quinn TC, Ronald AR, Sande MA (2006) Laboratory medicine in Africa: a barrier to effective health care. Clin Infect Dis 42(3): 377-382.

4. Mate KS, Rooney AL, Supachutikul A, Gyani G (2014) Accreditation as a path to achieving universal quality health coverage. Globalization and Health 10:68.

5. Perry L, Malkin R (2011) Effectiveness of medical equipment donations to improve health systems: how much medical equipment is broken in the developing world? Med Biol Eng Comput 49(7): 719-722.

6. (2010) Federal Democratic Republic of Ethiopia Ministry of Health. Ethiopian hospital reform implementation guidelines, Ethiopia. Volume 1.

7. Burtis CA, Bruns DE (2018) Tietz fundamentals of clinical chemistry and molecular diagnostics. $6^{\text {th }}($ edn. $)$. Elsevier Inc.

8. Boneno J, Fokakis M, Armbruster D (2005) Reagent Carryover Studies: Preventing Analytical errors with open clinical chemistry systems. Laboratory Medicine 36(11): 705-710.

9. (2012) Ethiopian Standard Agency. ES3617:2012. Ethiopian standard; Primary hospital requirements.

10. (2012) Ethiopian Standard Agency. ES 3614:2012. Ethiopian standard; General hospital requirements.

11. (2012) Ethiopian Standard Agency. ES3618:2012. Ethiopian standard; comprehensive specialized hospital requirements.

12. Getachew A, Cheneke W, Asres Y, Bekele S, Kebede E (2019) Assessment of coverage and quality of selected clinical chemistry tests among medical laboratories of health facilities in Jimma zone, South West Ethiopia. J Trop Med 2019: 5954313.

13. Peter TF, Shimada Y, Freeman RR, Ncube BN, Khine A, et al. (2009) The need for standardization in laboratory networks. Am J Clin Pathol 131(6): 867-874.

14. Ademe BW, Tebeje B, Molla A (2016) Availability and utilization of medical devices in Jimma zone hospitals, Southwest Ethiopia: a case study. BMC Health Serv Res 16: 287.

15. (2010) Medical Devices. Managing the Mismatch: An outcome of the priority medical devices project. Geneva: World Health Organization.

16. (2000) Guidelines for health care equipment donations. Geneva: World Health Organization.

17. Desale A, Taye B, Belay G, Nigatu A (2013) Assessment of laboratory logistics management information system practice for HIV/AIDS and tuberculosis laboratory commodities in selected public health facilities in Addis Ababa, Ethiopia. Pan African Medical Journal 15: 46.

18. (2017) Guidance for procurement of in vitro diagnostics and related laboratory items and equipment. Geneva: World Health Organization.

19. Mesfin EA, Taye B, Belay G, Ashenafi A, Girma V (2017) Factors affecting quality of laboratory services in public and private health facilities in Addis Ababa, Ethiopia. eJIFCC 28(3): 205-223. 
ISSN: 2574-1241

DOI: 10.26717/BJSTR.2021.34.005584

Rebuma Belete. Biomed J Sci \& Tech Res

(c) (P) This work is licensed under Creative

Submission Link: https://biomedres.us/submit-manuscript.php

$\begin{array}{ll}\text { BIOMEDICAL } & \text { Assets of Publishing with us } \\ \text { RESEARCHES } & \text { - Global archiving of articles } \\ & \text { - Immediate, unrestricted online access } \\ & \text { - Rigorous Peer Review Process } \\ & \text { - Authors Retain Copyrights }\end{array}$

